Pathologe 2017 · 38 (Suppl 2):S255

https://doi.org/10.1007/s00292-017-0293-x

Online publiziert: 25. April 2017

๑) Springer Medizin Verlag GmbH 2017

CrossMark

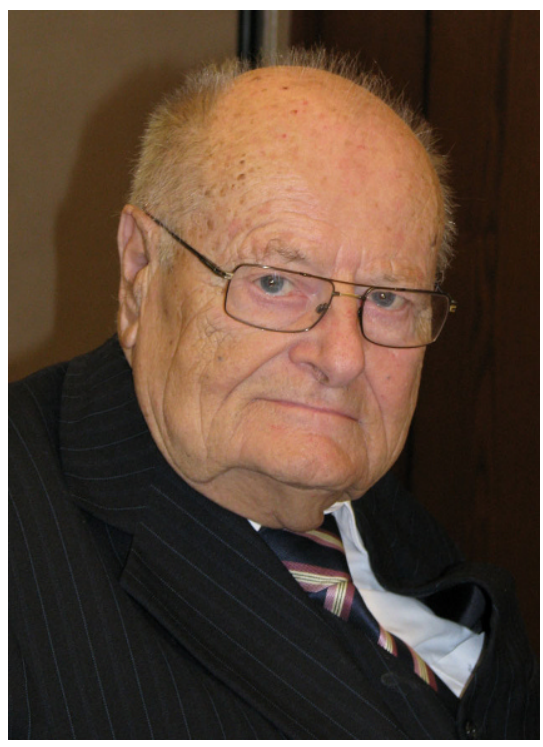

Günter Nothwang

Am 21. November starb Dr. med. Günter Nothwang, ehemaliger Chefarzt im $\mathrm{Pa}$ thologischen Institut des Kreiskrankenhauses Reutlingen.

Günter Nothwang wurde am 29. Juni 1926 als Sohn eines Postinspektors in Heilbronn geboren. Seine Vorfahren waren Bauern und er verbrachte seine Kinder- und Jugendjahre auf dem Lande. Als er 6 Jahre alt war, starb sein Vater. Die Gymnasialzeit wurde vom Zweiten Weltkrieg geprägt. Häufige Infektionskrankheiten und der daraus resultierende häufige Kontakt mit Ärzten und Krankenhäusern sowie seine Ausbildung zum Sanitätssoldaten während des Krieges festigten seinen Entschluss, Medizin zu studieren, obwohl ihn die Agrarwissenschaft oder die Musik ebenfalls gereizt hätten. Noch kurz vor Kriegsende geriet er in die Gefangenschaft der Franzosen.

Das Medizinstudium absolvierte er in Dillingen und an der Universität Würzburg, wurde er über das Thema „Zur

\title{
K. Sorger
}

Baden-Baden, Deutschland

\section{Günter Nothwang}

\subsubsection{6 - 21.11.2016}

Morphologie und Differenzialdiagnose der sogenannten atypischen Lymphogranulomatosen" promoviert und bekam eine der begehrten Assistentenstellen bei Prof. Eugen Kirch in der Pathologie.

Wegen dessen bevorstehender Emeritierung bewarb er sich in seiner Heimatstadt Heilbronn an den Städtischen Krankenanstalten bei Dr. Alfred Fischer, mit dem er 16 Jahre als Oberarzt und Stellvertreter des Chefs zusammenarbeitete und bis an sein Lebensende befreundet war. Da es nur an der Universität Heidelberg und bei der Stadt Stuttgart ein Rechtsmedizinisches Institut gab, befürwortete der Direktor des Heidelberger Instituts die Übertragung rechtsmedizinischer Aufgaben im Land- und Amtsgerichtsbezirk Heilbronn an die Kollegen des gerade frisch installierten Pathologischen Instituts. In Heilbronn heiratete er seine Frau Eva-Irene Wagner und genoss mit ihr und den später geborenen zwei Kindern, Susanne und Jürgen, ein glückliches Familienleben.

Am 1. Juli 1971 trat er seinen Dienst als Chefarzt des im Aufbau befindlichen Pathologischen Instituts der Kreiskrankenhäuser Reutlingen, Bad Urach und Münsingen an. Eine Bewerbung in Heilbronn nach dem Ausscheiden Dr. Fischers hatte er abgelehnt, weil er nicht zu seinem Freund Dr. Peter Holch in Konkurrenz treten wollte. Im Mai 1986 konnte die Arbeit in einem neu erbauten, modernen Institut, das von ihm geplant worden und dem Status eines Lehrkrankenhauses der Universität Tübingen angemessen war, fortgesetzt werden.

Nach 20-jähriger Tätigkeit als Chefarzt in Reutlingen wurde Günter Nothwang am 8. April 1991 in den Ruhestand verabschiedet. Von seinen ärztlichen Mitarbeitern wurde er als humorvoller, menschlicher und großzügiger Chef geschätzt, der eigentlich ein „Gemütsmensch“ war, aber auch einmal „auf den Tisch hauen“ konnte, jedoch nicht nachtragend war. Kurzum: ein „schwäbisches Urgestein“, bodenständig, direkt und herzlich. Für die täglichen Sorgen seiner Mitarbeiter und Mitarbeiterinnen hatte er immer ein offenes Ohr. Die Zusammenarbeit mit den klinischen Kollegen war von gegenseitigem Respekt geprägt.

Im (Un)ruhestand führte er weiterhin die amtsärztliche Leichenschau vor der Feuerbestattung im Krematorium durch. Daneben konnte er sich ausgiebig seinen Hobbys, der Musik und dem Pferdesport, widmen.

Ein schwerer Schlag war für ihn der Tod seiner lieben Frau 2002.

Nur wenige Monate vor seinem Tod hat er seinen 90. Geburtstag in totaler geistiger Frische, wenn auch körperlich beeinträchtigt, inmitten seiner Familie, seiner Freunde, ehemaliger Kollegen und Mitarbeiter sowie Anhängern des Pferdesports und der Musik gefeiert. Mit seinem Tod ist ein erfülltes Leben $\mathrm{zu}$ Ende gegangen. Alle, die ihn kannten, werden ihm ein ehrendes Andenken bewahren.

Karin Sorger
Baden-Baden

\section{Korrespondenzadresse}

Prof. Dr. K. Sorger

Heschmattweg 2A, 76534 Baden-Baden, Deutschland

karinsorger@web.de 